\title{
Algumas considerações sobre a modelagem hidrológica aplicada à gestão ambiental
}

\section{Some consideration about the hydrological modeling applied in the environmental management}

\section{Marcela Alves da Silva}

Universidade Federal da Paraíba, Centro de Ciências Exatas e da Natureza, Programa de Pós-Graduação em Geografia, Campus Universitário, João Pessoa-PB (CEP 58051-900).E-mail: marcelaalves2006@hotmail.com.

\begin{abstract}
Resumo. A modelagem de bacias hidrográficas é utilizada no gerenciamento dos recursos hídricos com o objetivo de compreender como diversos fatores ambientais presentes na bacia hidrográfica que afetam a disponibilidade e a qualidade da água. A modelagem de uma bacia hidrográfica é o ponto de partida para estudos referentes à dinâmica ambiental da mesma, possibilitando o melhor gerenciamento e aproveitamento de seus recursos naturais. Neste trabalho faremos uma breve discussão sobre as contribuições da modelagem hidrológica no planejamento e gestão de bacias hidrográficas, com o objetivo de demonstrar como esta ferramenta vem se tornando uma ótima alternativa para gestão ambiental, com auxílio das geotecnologias. Aprender a modelar é, antes de tudo, aprender a observar, a notar detalhes e a questionar. A questão dos recursos hídricos é, sem dúvida, fascinante e essencial para os dias de hoje, dada a necessidade cada vez maior de exploração desses recursos. A modelagem hidrológica surge como uma ferramenta capaz de antecipar acontecimentos e apontar alternativas que conduzam à manutenção da capacidade produtiva do ambiente.
\end{abstract}

Palavras-chave: Modelagem hidrológica; geotecnologia; gestão; bacia hidrográfica.

\begin{abstract}
The watershed modeling is used in the management of water resources in order to understand how various environmental factors present in the watershed that affects the availability and quality of water. The modeling of a watershed is the starting point for studies related to the same environmental dynamics, enabling better management and utilization of natural resources. In this work we use we will briefly discussion about the contributions of hydrological modeling in planning and watershed management in order to demonstrate how this tool has become a great alternative to environmental management, with the aid of geotechnology. Learning the model is first of all learn to observe, to notice details and questioning. The issue of water resources is not fascinating and essential for today doubt, given the increasing need for resource exploitation. The hydrologic modeling emerges as a tool to anticipate events and identify alternatives that lead to the maintenance of the productive capacity of the environment.
\end{abstract}

Keyword: Hydrologic modeling; geotechnology; management; watershed.

\section{Introdução}

Um modelo é a representação conceitual de um fenômeno e geralmente se refere a apenas algum aspecto do fenômeno. Um modelo hidrológico pode ser defi-
Recebido: 30/09/2014

Aceito: 10/10/2014

Publicado: 20/11/2014

Acesso aberto. Artigo completo. 
Brasil. A modelagem de bacias hidrográficas é utilizada no gerenciamento dos recursos hídricos com o objetivo de compreender como diversos fatores ambientais presentes na bacia hidrográfica afetam a disponibilidade e a qualidade da água. Os objetivos de um sistema de gestão dos recursos hídricos são particulares para cada região, sendo assim, as ferramentas de modelagem devem ser selecionadas de acordo com as características da área de interesse e os objetivos propostos (Cercuci e Mancuso, 2007).

Compreendendo que a gestão do território pode orientar o melhor uso do ambiente, modelos hidrológicos são importantes, pois podem simular a vazão e a qualidade da água dos rios por longos períodos de tempo. Esse tipo de análise permite a avaliação simultânea da disponibilidade de água e a sua qualidade de acordo com vários cenários de regimes de fluxo, regras de operação de transposições de água e descarga de efluentes, assim como mudanças de uso e ocupação do solo na bacia hidrográfica (Cercuci e Mancuso, 2007).

O objetivo deste trabalho é discutir da relação entre a modelagem hidrologica e sua contribuição para a gestão ambiental do territorio.

A Geografia é a ciência que fornece as bases teórico-metodológicas para as geotecnologias, e através do estudo da realidade definida pelo espaço geograficamente construído traz a necessidade do auxílio de um ferramental de apoio que seja significativo, uma vez que o avanço tecnológico tem causado maior influência na pesquisa geográfica, estando relacionado ao aparecimento das geotecnologias, em destaque dos Sistemas de Informação Geográfica - SIG e do Sensoriamento Remoto, sendo esta uma tecnologia que fornece grande parte dos dados para o estudo dos fenômenos espaciais. Mas é importante ressaltar que essas geotecnologias não valem apenas por si sós, estão inseridas em seus contextos e devem ser utilizadas de forma ética entre as ações humanas e o respeito ao meio ambiente (Fitz, 2008).

As geotecnologias têm se mostrado como ferramentas eficientes de auxílio à gestão de recursos hídricos. As imagens de satélite e arquivos digitais em diferentes formatos, entre os quais os shapefiles, são fontes de dados indispensáveis, permitindo menor custo e redução de tempo em trabalhos de campo para estudos de recursos hídricos (Silva Neto et al., 2013).

Uma definição ampla e universal aborda o SIG como sendo um sistema integrado para capturar, armazenar, manipular, analisar e exibir informações referentes às relações de natureza geográfica (Rezende, 2002). Um SIG tem a capacidade de processar dados gráficos e não gráficos (alfanuméricos), com ferramentas de análise espacial e modelagem de superfícies (Collischonn, 2000).

Atualmente, existem vários softwares disponíveis para o tratamento das informações espaciais e para a aplicação das técnicas de geoprocessamento, tanto gratuitos como comerciais. Entre os mais conhecidos, está o ArcGIS (ESRI), que possibilita a extração de dados do terreno de modo manual ou automático para análises mais específicas em relação às bacias hidrográficas.

A modelagem de uma bacia hidrográfica é o ponto de partida para estudos referentes à dinâmica ambiental da mesma, possibilitando o melhor gerenciamento e aproveitamento de seus recursos naturais.

Nessa perspectiva inclui-se o suporte dado pelas geotecnologias, que permitem o levantamento/elaboração, análise e execução, armazenamento e publicação dos dados ou informações geoespaciais gerados pelos diversos processos de modelagem hidrológica, já elaborados ou em fase de elaboração, ferramental digital intrínseco ao próprio planejamento territorial, conforme as normatizações e padronizações levantadas pela Infraestrutura Nacional de Dados Espacial - INDE (Decreto ${ }^{\circ}$ 6.666/2002).

Modelos hidrológicos utilizam dados de precipitação, temperatura, uso e ocupação do solo, tipo do solo, relevo, entre outros parâmetros, para simular a fase terrestre do ciclo hidrológico e a massa de poluentes levada até os rios através do escoamento superficial (Cercuci e Mancuso, 2007).

Para desenvolver o presente trabalho foi realizado um levantamento bibliográfico e uma revisão teórica sobre os temas tratados. Este levantamento bibliográfico contou com pesquisa em artigos científicos, monografias, sites especializados, livros que tratam sobre o tema, entre outros, 
que sirvam de embasamento para discussão sobre a modelagem hidrológica, análise e gestão ambiental, gestão de recursos hídricos. Levantamento e análise documental, de acordo com Cellard (2008), correspondem aos resquícios do passado, é tudo o que serve de testemunho. Neste estudo, a análise documental enfocará os documentos públicos presentes em arquivos governamentais (federal, estadual e municipal).

\section{Modelagem hidrológica e gestão am- biental}

Uma bacia hidrográfica é um sistema que compreende um volume de materiais, em sua maioria sólidos e líquidos, delimitado interno e externamente por todos os processos que a partir do fornecimento de água pela atmosfera, interferem no fluxo de matéria e energia de um rio ou de uma rede de drenagem. Esta abrange todos os espaços de circulação, armazenamento, e de saídas de água e do material por ela transportado, que mantém relações com esses canais (Rodrigues e Adami, 2005).

A análise de bacias hidrográficas passou a apresentar caráter mais objetivo a partir de 1945, com a publicação do trabalho do engenheiro hidráulico Robert E. Horton que procurou estabelecer as leis dos desenvolvimentos dos rios e suas bacias. É a ele a quem se deve a abordagem quantitativa das bacias de drenagem (Christofoletti, 1980). Analisar uma bacia hidrográfica sob o enfoque ambiental, significa considerar que se trata de uma totalidade sistêmica, formada pela interação e articulação de diversos sistemas ambientais (Rodriguez et al., 2001).

As bacias hidrográficas estão interligadas pelos divisores topográficos, formando uma rede em que cada um deles drena água, material sólido e dissolvido para uma saída comum, que pode ser outro rio de hierarquia igual ou superior, lago, reservatório ou oceano. É importante perceber que as bacias hidrográficas integram uma visão conjunta das condições naturais e das atividades humanas nela desenvolvidas (Cunha e Guerra, 2000).

Uma das preocupações mais recentes da Geografia é com a construção de uma conceituação de território que leve em consideração a ação de seus atores, o ser hu- mano em sociedade, promotor de transformações na via do sistema econômico, da política e estabelecimento de instituições. No bojo deste modo de repensar o território há, também, a necessidade de se incluir a natureza enquanto uma de suas partes integrantes, mas, evitando-se cair numa redução do conceito a ecossistemas regidos por leis naturais.

O território, conceito bem conhecido pelos geógrafos, permite analisar as repercussões da organização e dos funcionamentos sociais e econômicos sobre $\mathrm{o}$ espaço considerado.

A modelagem entendida como a criação de representações da superfície física ou artificialmente criadas através de processos matemáticos, há novos bancos de dados de organização e armazenamento de uma base de informações alfanuméricas, raster ou vetoriais, de fácil manuseio e segurança que sirva de subsidio em analises de bacias hidrográficas de impactos ambientais entre outros.

O uso integrado das geotecnologias potencializa sua contribuição como suporte à tomada de decisão durante o diagnóstico do cenário geoambiental atual, bem como para seu prognóstico projetando cenários futuros que em conjunto podem nortear ações de controle do uso e ocupação do solo.

A política ambiental no Brasil vem passando por inúmeras mudanças no âmbito de sua legislação e estrutura administrativa, caracterizando uma nova gestão do meio ambiente, principalmente após a formulação da Política Nacional do Meio Ambiente em 1981 (Lei no 6.938/1981) e da Constituição Federal de 1988.

A gestão ambiental no Século XXI está voltada para políticas públicas que levem em consideração não só a proteção/conservação ambiental, mas também o desenvolvimento regional a partir da condição da existência humana em suas peculiaridades e com problemáticas ambientais, sociais, culturais e políticas buscando uma melhor qualidade de vida para a população. A ideia de sustentabilidade que se torna necessária é a de que as riquezas naturais possam ser bem aproveitadas sem degradar tanto a natureza e possam trazer desenvolvimento. A sociedade do consumo sabe como produzir de modo sustentável, só não 
o faz por questões econômicas, por falta de uma política normativa fiscalizadora efetiva e também pela ausência de divulgação dos conhecimentos científicos.

A gestão ambiental consiste na administração dos recursos ambientais por meio de ações técnicas e institucionais, investimentos econômicos e o uso do aparato jurídico, com a finalidade de manter ou recuperar a qualidade de recursos e desenvolvimento social (Nobre e Garcia, 2013).

A gestão ambiental é assumida de maneira diferenciada pelos atores sociais e econômicos que intervém nesse processo. Ela conduz a visualização de pelo menos três enfoques: o poder público, com o papel de dirigir, conduzir e incentivar o processo de gestão; o da empresa, com o papel de aperfeiçoar e maximizar a eficiência, a eficácia e a efetividade econômica; e a sociedade civil e em particular os grupos e as comunidades sociais com o papel de potencializar a apropriação da natureza para garantir as suas necessidades básicas e sua lógica cultural, sob uma base geral da ação coletiva desenvolvida pelos indivíduos.

Almeida (2002) afirma que de uma forma geral, as teorias desenvolvimentistas, sejam neoliberais ou marxistas tem suas bases nas sociedades ocidentais e tem como objetivo propor ou "impor" modelos para o conjunto do mundo. De acordo com o autor, a ideia mestre de desenvolvimento socioeconômico é provocada pelos avanços teórico-científicos, assegurando o próprio crescimento e o progresso das virtudes humanas, das liberdades e dos poderes dos homens.

O planejamento do uso do solo sob a perspectiva ambiental pode ser tomada como um substrato das atividades humanas que nele se assentam e nele se desenvolvem buscando melhor qualidade de vida. O objetivo de planejamento de uso do solo é orienta os instrumentos metodológicos administrativos, legislativo e de gestão para o desenvolvimento de atividades num determinado espaço e tempo, incentivando a participação institucional e dos cidadãos (Vasconcellos et al., 2013).

A mobilização na gestão de recursos hídricos ocorreu principalmente por causa do crescimento econômico e populacional. A partir da década de 1950 houve grandes incentivos em industrialização e urbanização, o que levou ao inicio da crise ambiental, como resultado da degradação das condições de vida da população e dos sistemas naturais (Ruhoff, 2004).

Para Hidalgo (1992), qualquer alteração das propriedades físicas, químicas ou biológicas dos recursos naturais renováveis (solo, vegetação, ar, água, fauna), causada por alguma forma de energia ou elementos produzidos por atividades humanas é capaz direta ou indiretamente, de criar condições nocivas à saúde do homem, a sociedade e aos recursos naturais.

No Brasil, a gestão ambiental de recursos hídricos inicia-se praticamente com a aprovação da lei nacional de recursos hídricos em 1997 (Lei n ${ }^{\circ}$ 9.744/1997) e pela implantação de um sistema nacional de gerenciamento desses recursos, tendo a crescente preocupação com os problemas relacionados com a degradação dos recursos naturais e em particular com a degradação dos recursos hídricos no Brasil (Vieira e Ribeiro, 2010). Tem levado as entidades governamentais dedicadas a o planejamento e a gestão ambiental a concentrarem esforços na elaboração de projetos voltados ao equacionamento dos problemas associados ao uso múltiplo do recurso água.

De acordo com Beneti (1993) e Lanna (1993), a gestão de recursos hídricos fluviais vem sendo colocada como fator estratégico na política governamental de meio ambiente e de desenvolvimento devido ao elevado grau de alteração dos geossistemas e ecossistemas fluviais ocasionados pelas atividades socioeconômicas. Essas atividades por não terem sido coordenadas de maneira planejada, vêm comprometendo continuamente a disponibilidade e qualidade dos recursos hídricos.

A bacia hidrográfica tem sido adotada como unidade de planejamento e gestão em inúmeras pesquisas por permitir à análise dos fatores físicos circunscritos a sua área de drenagem e correlacioná-los com fatores de ordem antrópica. Nesse novo contexto as geotecnologias se encaixam com grande potencial de integração de dados subsidiando analises da paisagem em bacias hidrográficas. Considerando as alterações ambientais, se torna relevante para a geografia produzir informações que auxiliem no planejamento do uso e ocupação territorial (Leite et al., 2014). 
A realização de estudos voltados ao planejamento e gestão ambiental utilizam as bacias hidrográficas como unidade espacial de análise e são reconhecidas por Lanna (1995) como unidades ideais para a prática de gestão e planejamento ambiental por possibilitarem um estudo integrado do meio. Assim, as geotecnologias podem fornecer contribuições ao estudo das práticas sociais e do seu relacionamento com a dinâmica física e biológica do ambiente em que a sociedade se insere.

O conceito de bacia hidrográfica como unidade de planejamento e gestão ambiental é resultado do conhecimento das relações entre as características físicas de uma bacia de drenagem e a quantidade e qualidade das águas que chegam ao corpo hídrico, por outro lado as características de um corpo hídrico refletem as de sua bacia de drenagem, levando também em consideração todas as características químicas e biológicas do corpo hídrico (Araújo et al., 2009).

Para um fim de planejamento e gestão, pensar a bacia hidrográfica como unidade possibilita uma melhor leitura do quadro de potencialidades e fragilidades de uma paisagem por meio do diagnóstico ambiental (Rufo e Cristo, 2014).

As bacias hidrográficas podem ser tratadas como unidades geográficas onde os recursos naturais se integram. Nessa conjuntura ocorre a possibilidade de um estudo integrado dos elementos que formam a paisagem (geologia, geomorfologia, pedologia, biogeografia e atividades antrópicas) e que as mudanças bruscas ou gradativas em algumas dessas áreas, acarretará na funcionalidade do sistema, que busca sempre um equilíbrio entre a entrada e a saída de energia pelo fluxo hídrico (Teodoro et al., 2007).

É dentro desse contexto que entendemos a modelagem como uma ferramenta que auxilia na gestão dos recursos hídricos, de forma a adequar a utilização dos recursos, o controle e a proteção do meio e regular a prática, o uso, o controle e a conservação dos recursos (Ruhoff, 2004).

O desenvolvimento de estratégias de modelagem voltadas para atender os problemas identificados pelos comitês de bacias hidrográficas, por exemplo, é crítico para o sucesso no processo de modelagem.
Existem inúmeras ferramentas de modelagem disponíveis. Essas ferramentas podem ser utilizadas de forma integrada para oferecer uma estratégia de modelagem que seja eficiente do ponto de vista econômico e da qualidade ambiental.

\section{Considerações finais}

O modelo hidrológico pode ser aplicado na gestão dos recursos hídricos, contribuindo para o planejamento da agricultura irrigada de uma bacia hidrográfica, simulando diferentes cenários de usos construtivos, possibilitando o uso racional da água na bacia.

Considerando o caráter interdisciplinar das aplicações do Sistema de Informação Geográfica, a diversidade de conceito é bastante evidente, em particular a "Ciência da Geoinformação” vem produzindo modelos matemáticos que muitas vezes são apropriados por diversos campos do conhecimento. A partir da criação de um sistema de modelagem, sua implementação é facilitada já que tanto a estrutura do banco de dados quanto os métodos e funções necessárias já estão especificados.

Aprender a modelar é antes de tudo, aprender a observar, a notar detalhes e a questionar. A questão dos recursos hídricos é sem dúvida fascinante e essencial para os dias de hoje, dada à necessidade cada vez maior de exploração dos recursos. A modelagem hidrológica surge como uma ferramenta capaz de antecipar acontecimentos e apontar alternativas que conduzam à manutenção da capacidade produtiva do ambiente.

As tecnologias de geoprocessamento mostraram-se alternativas viáveis, de baixo custo e menor tempo para a obtenção dos dados da bacia em relação aos métodos de levantamentos convencionais.

Em cada sistema ambiental, sejam os geossistemas ou os ecossistemas, é possível aprender características assumidas pela projeção das relações internas, dentro de uma visão de totalidade. O nível de resistência, a autorregulação, a vulnerabilidade e a capacidade de suporte são características intrínsecas a análise de sistemas. A utilização dessa abordagem nos diagnósticos ambientais de bacias hidrográficas pode 
ajudar sobremaneira na condução do planejamento e tomada de decisão.

\section{Referências}

Almeida, L. T. O debate internacional sobre instrumentos de política ambiental e questões para o Brasil. Anais do II Encontro ECOECO, Araraquara, 2002.

Araújo, L. E.; Santos, M. J.; Duarte, S. M.; Oliveira, E. M. Impactos ambientais em bacias hidrográficas: O caso da Bacia do Rio Paraíba. TECNO-LÓGICA, v. 13, p. 109-115, 2009.

Beneti, A. O meio ambiente e os recursos hídricos. In: Tucci, C. E. M. (Org.). Hidrologia ciência e aplicação. Porto Alegre: Edusp, 1993.

Brasil. Leis, Decretos etc. Lei $\mathbf{n}^{\mathbf{0}}$ 6.938, de 31 de agosto de 1981. Dispõe sobre a Política Nacional do Meio Ambiente, seus fins e mecanismos de formulação e aplicação, e dá outras providências. Disponível em: $<$ http://www.planalto.gov.br/ccivil_03/leis/1693 8.htm>. Acesso em: 14 set. 2014.

Brasil. Leis, decretos etc. Constituição da República Federativa do Brasil de 1988. Disponível em: <http://www.planalto.gov.br/ ccivil_03/constituicao/constituicao.htm>. Acesso em: 14 set. 2014.

Brasil. Leis, decretos etc. Lei $\mathbf{n}^{\mathbf{0}} \mathbf{9 . 4 3 3}$, de 8 de janeiro de 1997. Institui a Política Nacional de Recursos Hídricos, cria o Sistema Nacional de Gerenciamento de Recursos Hídricos, regulamenta o inciso XIX do art. 21 da Constituição Federal, e altera o art. $1^{\circ}$ da Lei $n^{\circ} 8.001$, de 13 de março de 1990, que modificou a Lei $\mathrm{n}^{\circ}$ 7.990, de 28 de dezembro de 1989. Disponível em: <http://www.planalto.gov.br/ccivil_03/leis/ L9433.htm>. Acesso em: 14 set. 2014.

Brasil. Leis, decretos etc. Decreto $n^{\circ}$ 6.666, de 27 de novembro de 2008. Institui, no âmbito do Poder Executivo federal, a Infra-Estrutura Nacional de Dados Espaciais - INDE, e dá outras providências. Disponível em: $<$ http://www.planalto.gov.br/ccivil_03/_Ato200 7-2010/2008/Decreto/D6666.htm>. Acesso em: 14 set 2014 .

Cellard, A. A análise documental. Petrópolis: Vozes, 2008.

Cercucci, M.; Mancuso, M. Análise de uma metodologia flexível e dos aspectos de interesse para a modelagem hidrológica da Bacia Hidrográfica do Rio Cubatão. Anais do XVII Simpósio Brasileiro de Recursos Hídricos, São Paulo, 2007.

Christofoletti, A. Geomorfologia. 2. ed. São Paulo: Edgard Blucher, 1980.
Collischonn, W. Simulação hidrológica de grandes bacias. Porto Alegre: Universidade Federal do Rio Grande do Sul, Instituto de Pesquisas Hidráulicas, 2001. (Tese de doutorado).

Cunha, S. B.; Guerra, A. J. T. Geomorfologia e meio ambiente. Rio de Janeiro: Bertrand Brasil, 2000.

Fitz, P. R. Geoprocessamento sem complicação. São Paulo: Oficina de Texto, 2008.

Hidalgo, P. Diagnóstico socioeconômico. João Pessoa: PRM/Metroplan/AGP-RS, 1992.

Lanna, A. E. L. Gerenciamento de bacia hidrográfica: aspectos conceituais e metodológicos. Brasília: IBAMA, 1995.

Lanna, A. E. L. Gestão dos recursos hídricos. In: Tucci, C. E. M. (Org.). Hidrologia: ciência e aplicação. Porto Alegre: Edusp, 1993.

Leite, E. F.; Nunes, A. B.; Costa, J. F.; Nunes, J. C.; Barros, M. L. Panorama das condições ambientais na Bacia Hidrográfica do Rio Areias, Tocantins. Interface, v. 7, p. 117-126, 2014.

Nobre, M. F.; Garcia, G. J. O zoneamento ecológico-econômico como instrumento de planejamento e gestão ambiental. In: Silva, M. R. F.; Carvalho, R. G.; Grigio, A. M.; Dias, N. S. (Org.). Gestão ambiental: caminhos para uma sociedade sustentável. São Paulo: Editora Livraria da Física, 2013.

Rennó, C. D.; Soares, J. V. Conceitos básicos de modelagem hidrológica. Santa Maria: INPE, 2008.

Rezende, J. F. R. Gestão de informações utilizando a tecnologia de geoprocessamento para o Projeto Jaíba - Etapa II. Belo Horizonte: Universidade Federal de Minas Gerais, 2002. (Monografia de Especialização).

Rodrigues, M. C.; Adami, S. Técnicas fundamentais para o estudo da bacia hidrográfica. São Paulo: Oficina de Textos, 2005.

Rodriguez, J. M. M.; Silva, E. V.; Leal, A. C. Planejamento ambiental de bacias hidrográficas desde a visão da geoecologia da paisagem. In: Figueiró, A. S.; Foleto, E. (Org.). Diálogos em Geografia Física. Santa Maria: UFSM, 2001.

Rufo, R. L. T.; Cristo, S. S. V. Sensoriamento remoto aplicado na análise do uso e ocupação da Bacia Hidrográfica do Córrego Titira, Porto Nacional, Tocantins. Interface, v. 7, p. 47-60, 2014.

Ruhoff, A. L. Gerenciamento de recursos hidrícos em bacias hidrógraficas: modelagem ambiental com a simulação de cenários preservacionistas. Santa Maria: UFSM, 2014.

Silva Neto, A. F.; Guimarães, C. L.; Araújo, J. S.; Araújo, J. S. Geotecnologia para caracterização morfométrica de bacia hidrográfica. Anais XVI Simpósio Brasileiro de Sensoria- 
mento Remoto - SBSR, Foz do Iguaçu, INPE, 2013.

Teodoro, V. L. I.; Texeira, D.; Costa, D. J. L.; Fuller, B. B. O conceito de bacia hidrográfica e a importância da caracterização morfométrica para o entendimento da dinâmica ambiental local. Revista Uniara, n. 20, p. 137-156, 2007.

Vasconcelos, V. V.; Hadad, R. M.; Martins Júnior, P. P. Zoneamento EcológicoEconômico: objetivos e estratégias de política ambiental. Gaia Scientia, v. 7, p. 119-132, 2013.

Vieira, Z. M. C. L.; Ribeiro, M. M. R. Mudando o paradigma: A gestão de recursos hídricos no Brasil. In: Paz, R. J.; Luna, R. G.; Farias, T. (Org.). Gestão ambiental: o caminho para a sustentabilidade. João Pessoa: Ed. Universitária/UFPB, 2010. 